\title{
Author Correction: Macrophages confer resistance to PI3K inhibitor GDC-0941 in breast cancer through the activation of NF-KB signaling
}

Muhammad Waqas Usman', Jing Gao', Tiezheng Zheng ${ }^{2}$, Chunhua Rui', Ting Li', Xing Bian', Hailing Cheng ${ }^{1}$, Pixu Liu, ${ }^{1,3}$ and Fuwen Luo ${ }^{1}$

\section{Correction to: Cell Death \& Disease} https://doi.org/10.1038/s41419-018-0849-6, published online 24 July 2018

Since publication of this article, the authors have noticed the following errors:

(1) Figure 3c, the image is correct but the authors mistakenly provided incorrect figure legend. The correct figure legend is included below along with the original figure.

(2) Supplementary Fig. S2, the authors mistakenly provided the data from ELISA analysis of TNF $\alpha$ and IL-6 in media from co-cultured 4T1 and RAW264.7 cells. As stated in the main text, data from ELISA analysis of TNF $\alpha$ and IL- 6 in 4T1 tumors from
Balb/c mice treated with GDC-0941 should be provided. The correct figure and figure legend are included below.

(3) The authors noticed an error in the manuscript in which "RAW276.7" should be "RAW264.7".

The corrections do not alter the conclusions of the paper. The authors apologize for any inconvenience caused.

This has been corrected in both the PDF and HTML versions of the Article.

Published online: 24 June 2019

Correspondence: Hailing Cheng (hailingcheng_dmu@163.com) or

Pixu Liu (pixu_liu@dmu.edu.cn) or Fuwen Luo (fuwenluo@aliyun.com)

${ }^{1}$ Cancer Institute, Department of Acute Abdomen Surgery, The Second

Hospital of Dalian Medical University, Institute of Cancer Stem Cell, Dalian

Medical University, Dalian 116044, China

2Department of Physiology, Institute of Basic Medical Sciences, Dalian Medical

University, Dalian 116044, China

${ }^{3}$ College of Pharmacy, Dalian Medical University, Dalian 116044, China

These authors contributed equally: Muhammad Waqas Usman, Jing Gao,

Tiezheng Zheng

Edited by J. Chipuk

(c) (i) Open Access This article is licensed under a Creative Commons Attribution 4.0 International License, which permits use, sharing, adaptation, distribution and reproduction in any medium or format, as long as you give appropriate credit to the original author(s) and the source, provide a link to the Creative Commons license, and indicate if changes were made. The images or other third party material in this article are included in the article's Creative Commons license, unless indicated otherwise in a credit line to the material. If material is not included in the article's Creative Commons license and your intended use is not permitted by statutory regulation or exceeds the permitted use, you will need to obtain permission directly from the copyright holder. To view a copy of this license, visit http://creativecommons.org/licenses/by/4.0/. 


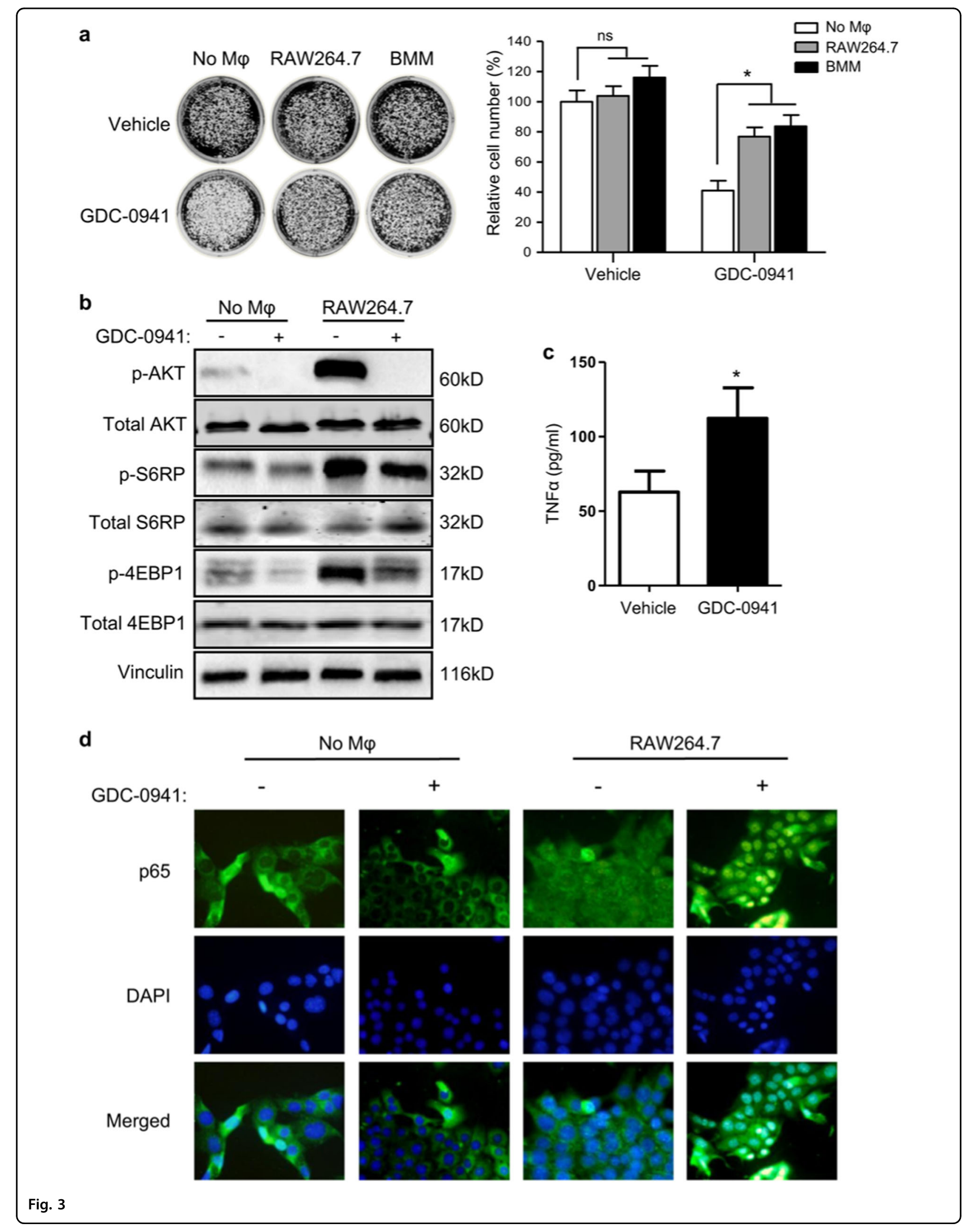

